\title{
Metodologia para planejamento de um de sistema cicloviário
}

\author{
Pablo de Barros Cardoso ${ }^{1}$ e Vânia Barcellos Gouvêa Campos²
}

\begin{abstract}
Resumo: Neste trabalho apresenta-se uma metodologia para planejamento de um sistema cicloviário, servindo como base para órgãos municipais na implantação destes sistemas visando fomentar o uso da bicicleta como forma alternativa de transporte diário ao trabalho e por motivo estudo. A proposta da metodologia partiu, inicialmente, da análise de parâmetros que são utilizados em métodos que avaliam vias cicláveis ou rotas. Após este estudo, foi aplicada uma pesquisa junto a ciclistas com o objetivo de identificar quais eram suas rotas usuais e quais os parâmetros mais importantes para escolha de uma determinada rota nos seus deslocamentos diários. Assim sendo, do cruzamento destas duas bases de informações, foi possível definir indicadores para a avaliação de segmentos viários, a partir do cálculo de um índice denominado de Índice de Adequação do Segmento para viagens por bicicletas. Este índice possibilita definir, numa rede viária, que segmentos são mais apropriados para fazerem parte de um sistema cicloviário.
\end{abstract}

Palavras-chave: vias cicláveis, indicadores, avaliação.

\begin{abstract}
This paper presents a methodology for planning a bikeway system, for supporting the municipality in the implementation of these systems in order to promote the use of bicycles, especially, as an alternative way of daily transport to work and to study. The proposed methodology set out analyzing parameters that are used in methods for assessing cycle lanes. After this review, a survey was conducted to the cyclists in order to identify their usual routes and which the most important parameters in choosing a route from its origin to its destination in daily commute. Therefore, the association of these two researches gave the support to define indicators for assessing road segments for the calculation of an index defined as Index of Adequacy of the Segment for travelling by bicycle. This index allows defining which segments of a road network are suited to be part of a bikeway system.
\end{abstract}

Keywords: bike lanes, indicators, evaluation.

\section{INTRODUÇÃO}

De acordo com GEIPOT (2001), um sistema cicloviário é composto por uma rede integrada de ciclovias, ciclofaixas e/ou vias compartilhadas interconectadas e interligando pólos geradores de viagens ou pólos de referência, formadas por elementos (terminais, equipamentos, transposições, etc) que atendam às necessidades e conveniências dos usuários ciclistas em seus deslocamentos nas áreas urbanas.

Em busca da mobilidade sustentável, muitas cidades no Brasil têm procurado desenvolver sistemas cicloviários, como forma de incentivar os deslocamentos diários da população, principalmente, em viagens por motivo trabalho, estudo e compras. Porém, observa-se que alguns sistemas apresentam falhas na sua concepção e por isso o objetivo de fazer crescer a demanda por este modo de transporte acaba por não ser atingido.

Experiências em sistemas cicloviários em países, principalmente da Europa, como Holanda, Dinamarca, França e Alemanha, mostram que é possível transformar a bicicleta num meio de transporte diário, substituindo se possível o veículo particular, principalmente, em áreas onde a bicicleta se mostra como meio mais rápido do que o automóvel.

Desta forma, neste trabalho, se propõe uma metodologia de apoio a prefeituras, principalmente, de médias e

\footnotetext{
1 Pablo de Barros Cardoso, Departamento de Administração,

UNIGRANRIO. (pdbcardoso@gmail.com)

2 Vania Barcellos Gouvêa Campos, Departamento de Engenharia,

Instituto Militar de Engenharia. (vania@ime.eb.br)

Manuscrito recebido em 17/05/2016 e aprovado para publicação em $27 / 09 / 2016$

Este artigo é parte de TRANSPORTES v. 24, n. 4, 2016. ISSN: 2237-1346 (online). DOI:10.14295/transportes.v24i4.1158
}

grandes cidades, para planejamento de um sistema cicloviário. Esta metodologia tem como objetivo avaliar segmentos viários quanto a sua adequabilidade na composição de uma rede cicloviária. Para isto, fez-se inicialmente, uma revisão bibliográfica sobre métodos de avaliação de vias cicláveis ou rotas usualmente utilizadas, onde foram identificados os principais parâmetros de análise. Estes trabalhos apresentam diferentes formas de quantificação e classificação de segmentos ou rotas.

Visando definir indicadores que poderiam ser utilizados no planejamento cicloviário em cidades brasileiras, foi feita uma pesquisa com usuários regulares de bicicletas, residentes no Rio de Janeiro. Assim, após as análises (revisão bibliográfica e pesquisa) foram definidos cinco indicadores de avaliação e a respectiva forma de medi-los. Com os valores dos indicadores por segmento viário define-se o índice de adequação do segmento avaliando assim, sua inclusão, ou não, no sistema, ou identificando melhorias a serem feitas.

Neste contexto, este artigo apresenta na seção 2, um resumo da revisão bibliográfica realizada e na seção 3 uma síntese da pesquisa com ciclistas. A metodologia proposta encontra-se na seção 4 e uma aplicação da mesma na seção 5 ; e algumas considerações na seção 6.

\section{REVISÃO BIBLIOGRÁFICA}

Conforme mencionado, para desenvolvimento da metodologia, fez-se inicialmente uma revisão de métodos utilizados para avaliar sistemas cicloviários. Nesta revisão buscou-se identificar os parâmetros propostos nos métodos, identificando quais os mais utilizados.

A revisão evidenciou que os métodos enfatizam elementos que aumentam a segurança dos ciclistas nos deslocamentos e que geram maior conforto na utilização das vias. 
Tabela 1. Parâmetros de Segurança

\begin{tabular}{|c|c|}
\hline Número de Faixas por Via & 7 \\
\hline Ciclofaixa na Via & 6 \\
\hline Ciclovia na rota & 6 \\
\hline Estacionamento na via paralelo ao fluxo de movimentação da via & 6 \\
\hline Limite de Velocidade para Veículos Automotores & 6 \\
\hline Volume Médio de Tráfego & 5 \\
\hline Diferença entre as velocidades médias dos ciclistas e dos veículos automotivos & 2 \\
\hline Distância de Visibilidade & 5 \\
\hline Grau de Experiência do Ciclista & 2 \\
\hline Largura da Faixa na Via & 4 \\
\hline Percentual de Veículos Pesados na Via & 2 \\
\hline Existência nas vias de barreiras para controlar o tráfego & 1 \\
\hline Faixa de Conversão a Direita & 2 \\
\hline Existência de meio-fio & 2 \\
\hline Garagens Residenciais ou Comerciais & 2 \\
\hline Largura do Acostamento & 3 \\
\hline Nível de Serviço da Via para veículos motorizados & 2 \\
\hline Número de Acessos Não Controlados de Veículos Automotivos & 1 \\
\hline Vias destinadas ao trânsito de bicicletas compartilhadas com outros veículos não motorizados e pedestres & 1 \\
\hline Acessos a direita para a calçada & 3 \\
\hline Canteiro Central & 3 \\
\hline Canteiro Central com baias para conversão a esquerda & 1 \\
\hline Curvas Horizontais & 3 \\
\hline Excesso de detritos nas Vias & 1 \\
\hline Existência de pólos geradores de viagem (fábricas, shoppings, estações de transporte público, escolas) & 1 \\
\hline Faixa Central para conversão a esquerda & 3 \\
\hline Falhas Causadas por Obras dos Departamentos de Águas, Esgotos e Eletricidade & 1 \\
\hline Iluminação da Via & 4 \\
\hline Número de cruzamento com passagem de pedestres & 1 \\
\hline Número de Residências ao longo da Via & 2 \\
\hline Número de veículos entrando a direita em vias de menor tráfego e cruzamentos & 1 \\
\hline Policiamento ao longo da rota & 1 \\
\hline Ponto de ônibus na Via & 1 \\
\hline Quantidade de ciclistas usando a via & 1 \\
\hline Rotas com poucos trechos compartilhados com veículos motorizados & 1 \\
\hline Rotas com superfícies escorregadias & 1 \\
\hline Rotas que não passem pelas vias mais urbanizadas & 1 \\
\hline Uso do solo - Comercial e Industrial & 3 \\
\hline Vias com riscos de acidentes entre motos e carros & 1 \\
\hline
\end{tabular}

Além destes dois fatores, as condições de projeto e superfície da via, e sinalização também foram observados.

No total, foram analisados treze trabalhos e identificou-se um conjunto de 73 parâmetros. Os fatores de segurança são mais evidentes nos métodos de Dixon(1996), Landis (1997) e BCI (FHWA,1998). Segurança e condições de superfície da via são enfatizados nos métodos de Epperson (1994), BSIR( Davis, 1987) e RCI( Eddy, 1997). Conforto e segurança são considerados mais fortemente nos trabalhos de Vandebulke (2009), Ergot (2011); e Monteiro (2011). A sinalização e a segurança são os principais parâmetros utilizados pelo método do HCM (TRB, 2010) e Hei- nen (2010). Ressalta-se que apesar da ênfase dada pelos métodos a alguns fatores, outros são considerados em menor escala.

As Tabelas 1 e 2 apresentam os parâmetros encontrados nos métodos divididos respectivamente, nos quatro conjuntos de fatores considerados: segurança, conforto e condições de projeto/superfície da via e sinalização. Além disto, apresenta-se à esquerda em cada tabela o número de autores/métodos que utilizaram o parâmetro para avaliação de segmentos em sistemas cicloviários. 
Tabela 2. Parâmetros de conforto, projeto e sinalização

\begin{tabular}{l|c}
\hline \multicolumn{1}{c}{ Parâmetros de Conforto } & $\mathbf{7}$ \\
\hline Aclive & $\mathbf{2}$ \\
\hline Distância percorrida no aclive & $\mathbf{5}$ \\
\hline Instalação para guardar e estacionamento de bicicletas & $\mathbf{3}$ \\
\hline Integração com o transporte público ao longo da rota & $\mathbf{2}$ \\
\hline Rotas que incluam vias mais distantes do trânsito com maior volume & $\mathbf{3}$ \\
\hline Arborização da Via & $\mathbf{3}$ \\
\hline Instalação de chuveiro e vestiários nos destinos das rotas & $\mathbf{1}$ \\
\hline Tempo de espera nos cruzamentos sinalizados & $\mathbf{1}$ \\
\hline Tempo de viagem de bicicleta na rota escolhida & $\mathbf{1}$ \\
\hline Velocidade do Vento & $\mathbf{6}$ \\
\hline \multicolumn{1}{c|}{ Parâmetros de projeto e superfície da via } & $\mathbf{4}$ \\
\hline Grelhas de Drenagem (Bueiros) & $\mathbf{3}$ \\
\hline Acostamento & $\mathbf{2}$ \\
\hline Buracos nas Vias & $\mathbf{3}$ \\
\hline Condição de Pavimentação da Via & $\mathbf{5}$ \\
\hline Cruzamento de Ferrovias & \\
\hline Deformações nas Vias (desgastes, remendos e rachaduras) & $\mathbf{5}$ \\
\hline Número de Interseções sinalizadas nas vias (prioridades e ações) & $\mathbf{6}$ \\
\hline Sinalização de Trânsito ao longo da Via & $\mathbf{1}$ \\
\hline Semáforos para ciclistas & $\mathbf{5}$ \\
\hline Sinalização das Interseções entre Pedestres e Ciclistas & $\mathbf{4}$ \\
\hline Sinalização especial para ciclista & $\mathbf{2}$ \\
\hline Sinalização que controlem o fluxo de bicicleta e veículos automotivos & \\
\hline
\end{tabular}

Observa-se que os parâmetros mais utilizados em relação ao fator segurança foram: (i)número de Faixas por Via, (ii) Ciclofaixa na Via, (iii)Ciclovia na rota, (iv)Estacionamento na via, (v) Limite de Velocidade para Veículos Automotores e (vi) Volume Médio de Tráfego. Em relação ao fator conforto: (i) aclive e (ii) instalação para guardar e estacionar de bicicletas. Na questão de condições de projeto/superfície: (i)Bueiros e (ii) deformações na via são os mais considerados. E quanto a sinalização os mais utilizados foram : (i)Número de Interseções sinalizadas nas vias e (ii) Sinalização das Interseções entre Pedestres e Ciclistas.

Além dos métodos de avaliação de vias, FernándezHeredia et al., (2014) observam a existência de estudos mais recentes, sobre as atitudes e percepções dos ciclistas, com a finalidade de quantificar a influência de diferentes fatores na decisão de escolha pelo modo cicloviário em viagens pendulares.

Também, pesquisas com usuários de bicicletas em cidades brasileiras (Ministério das Cidades, 2007; Kirner e Sanches, 2008; Providelo e Sanches, 2011, Magalhães e Palhares, 2013) identificaram algumas variáveis que influenciam a decisão de escolha da bicicleta para viagens pendulares. Dentre elas, as principais foram: largura da faixa de rolamento das vias, velocidade de veículos motorizados, visibilidade e número de interseções, estado de conservação do pavimento e topografia.

Segadilha e Sanches (2014) realizaram um estudo na cidade de São Carlos utilizando GPS para avaliar os caminhos utilizados pelos ciclistas. Neste trabalho, puderam identificar a escolha de itinerários e compará-los com os caminhos mínimos, e cada participante também respondeu a um questionário sobre a importância de vários fatores para a escolha de suas rotas. Sete fatores foram identificados como os mais importantes: número de caminhões, número de ônibus, volume de tráfego, velocidade do tráfego, iluminação pública, segurança, e qualidade do pavimento.
Magalhães et al (2015) apresentam uma proposta metodológica para a identificação de rotas cicláveis nas quais as condições de circulação adversas percebidas por usuários de bicicletas são minimizadas. Com esta finalidade, o critério de declividade de FHWA (1979) e o método de nível de serviço para bicicletas de Dixon (1996) foram escolhidos para avaliar o nível de serviço para ciclistas em vias arteriais e coletoras.

Assim, prosseguindo na definição dos indicadores a serem considerados na metodologia, e buscando associar a visão/escolha do ciclista com o observado nos métodos de avaliação revistos, realizou-se uma pesquisa com usuários regulares de bicicletas em viagens pendulares que é apresentada a seguir.

\section{PESQUISA COM USUÁRIOS}

A pesquisa com usuários foi realizada na cidade do Rio de Janeiro visando identificar os principais parâmetros de escolha de rotas por ciclistas habituais. A amostra mínima foi calculada com base na estimativa da proporção populacional. A Equação 1 define o tamanho da amostra para uma estimativa confiável da proporção populacional (p), conforme apresentado por Richardson (1999), quando não se conhece a população.

$$
n=\frac{Z_{\alpha / 2}^{2} \cdot p \cdot q}{E^{2}}
$$

Onde:

$\mathrm{n}=$ Número de indivíduos na amostra

$\mathrm{Z}_{\alpha / 2}=$ Valor crítico que corresponde ao grau de confiança

$\mathrm{p}=$ Proporção populacional de indivíduos que pertence à categoria de estudo 
$\mathrm{q}$ = Proporção populacional de indivíduos que não pertence à categoria estudada $(\mathrm{q}=1-\mathrm{p})$.

$\mathrm{E}=$ Margem de erro ou erro máximo de estimativa. Identifica a diferença máxima entre a Proporção amostral e a verdadeira Proporção populacional (p).

De acordo com dados do Plano Diretor de Transportes Urbanos (PDTU, 2003), os deslocamentos com bicicletas na região Metropolitana do Rio de Janeiro representam $3 \%$ do total, sendo então $\mathrm{p}=0,03$, considerando o grau de confiança de $95 \%$, então o Valor Crítico $Z \alpha / 2$ é 1,96, q=1$\mathrm{p}=0,97$ e o erro máximo de estimativa (E) de $\pm 4 \%$ (ou $0,04)$, temos então a amostra mínima igual a:

$$
n=\frac{1,96^{2} \times 0,03 \times 0,97}{0,04^{2}}=69,89 \cong 70 \text { pesquisas }
$$

Assim, um questionário online foi desenvolvido contendo 9 (nove) perguntas e foi respondido por 75 (setenta e cinco) ciclistas. Neste questionário buscou-se identificar as principais características das rotas utilizadas. Neste, perguntou-se sobre a finalidade das viagens rotineiras por bicicletas e a frequência das mesmas durante a semana, a origem e o destino destas viagens, o tempo de percurso, qual o percurso (ruas utilizadas) e o período do dia. Havia uma pergunta sobre porque utilizava a rota, esta continha algumas opções de resposta, como: menor tempo, segurança, mais agradável, menor esforço, entre outras; e uma pergunta aberta sobre quando deixava de usar a bicicleta para fazer esta viagem. Para assegurar que as respostas fossem de usuários regulares de bicicletas em viagens pendulares, a pesquisa foi aplicada num grupo de ciclistas cadastrados na ONG Transporte Ativo e num grupo de trabalhadores de uma empresa com perfil de usuários diário de bicicletas. Isto possibilitou obter informações de pessoas que efetivamente usavam este modo em seus deslocamentos diários, e assim, as respostas não seriam baseadas em intenções. var que:

A partir das respostas ao questionário pode-se obser-

- $65,3 \%$ dos usuários utilizavam a bicicleta como meio de transporte nos deslocamentos para universidade/trabalho e 30,7\% usavam para realizar compras.

- 93,3\% utilizavam a bicicleta em seus deslocamentos diários três ou mais vezes por semana;

- 54,7\% dos deslocamentos possuíam como origem os bairros do Flamengo, Botafogo, Humaitá, Catete e Laranjeiras. Outros $12 \%$ (segundo maior grupo) possuíam como origem os bairros do Maracanã, Tijuca, Vila Isabel, Grajaú e São Cristóvão.

- 61,3\% dos deslocamentos diários tem como destino as regiões do Centro

- $72 \%$ das viagens levam entre 10 e 39 minutos;

- $55 \%$ escolhem a rota pelo menor tempo de viagem e $45 \%$ pela segurança que a rota apresenta;

- 65,3\% dos usuários desistem de utilizar a bicicleta em seus deslocamentos diários quando está chovendo; $38,7 \%$ desiste quando tem que transportar passageiro e $37,3 \%$ desiste quando tem que transportar muita carga.

A preocupação quanto à segurança, observada por $45 \%$ dos entrevistados, revelou que estes utilizam uma rota mais segura, mesmo aumentando a distância percorrida (conforme dados da pesquisa, os usuários que privilegiam a segurança faziam um percurso até $30 \%$ superior a rota de menor distância) e o tempo gasto nas viagens pendulares (os ciclistas utilizavam rotas com até 20 minutos a mais no tempo de viagem, privilegiando rotas mais seguras o que corresponde à $35 \%$ do tempo total de viagem).

\section{METODOLOGIA PARA PLANEJAMENTO DE UM SISTEMA CICLOVIARIO}

O principal objetivo da metodologia é servir de instrumento de análise da rede viária existente para definição de que vias podem compor um sistema cicloviário, compreendendo a implantação de vias compartilhadas, ciclovias ou ciclofaixas, além de uma sinalização eficaz neste sistema. Para tanto, foram tomados como base os parâmetros identificados na revisão bibliográfica deste estudo e na pesquisa realizada com ciclistas, descrita na seção 3 deste artigo.

A revisão bibliográfica mostrou que os estudos sobre sistemas cicloviários enfatizam elementos que aumentem a segurança dos ciclistas nos deslocamentos e que gerem maior conforto. Os fatores relacionados à pavimentação e sinalização foram também observados porém, considerouse que estes devem estar no processo de melhorias nos segmentos que comporão o sistema cicloviário.

A segurança foi também observada pelos ciclistas na pesquisa realizada neste trabalho (seção 3). Além disso, observou-se que os ciclistas optam, em sua maioria (55\% dos entrevistados), por uma rota de menor distância entre os pontos de origem e destino.

Assim, a metodologia considera que o sistema cicloviário seja planejado a partir da identificação dos pólos geradores de viagens no local (cidade/ região) onde será implantado (conforme sugere GEIPOT, 2001), na identificação da rota de menor caminho entre estes pólos geradores de viagens e na qualificação dos segmentos que compõem estas rotas de acordo com os indicadores propostos.

Diante disto, foram definidos cinco indicadores relacionados a segurança e conforto para compor o índice de adequação do segmento: largura efetiva da via, estacionamento na via, volume médio de tráfego, velocidade máxima na via e aclive.

A metodologia proposta, aplicável em qualquer cidade, compreende cinco etapas:

- Etapa 1: Definição da área, e respectivo sistema viário, onde será estudada a viabilidade de implantação do sistema cicloviário, identificando os principais pólos geradores de viagens ou pólos de referência.

- Etapa 2: Identificar os caminhos mínimos (menor distância) entre todos os pólos geradores de viagens.

- Etapa 3: Qualificação de cada segmento de via/rota que compõe cada caminho mínimo quanto adequação dos mesmos à inclusão no sistema cicloviário.

- Etapa 4: Identificar aos segmentos que tiveram a classificação inadequada e recalcular o caminho verificando se há vias próximas que substituam o segmento inadequado.

- Etapa 5: Analisar e sugerir melhorias nos segmentos que compõem o sistema cicloviário quanto aos índices e indicadores avaliados.

A seguir são descritas cada uma das etapas. 


\subsection{Etapa 1: Definição da Área de Estudo}

Esta etapa compreende o levantamento dos dados referentes à área onde se estudará a implantação de um sistema cicloviário com as seguintes atividades:

- Mapa geo-referenciado da área com o sistema viário e suas características de infraestrutura;

- Delimitação da área de estudo;

- Identificação dos pólos geradores de viagens.

Segundo o DENATRAN (2001), os pólos geradores de viagens e tráfego são empreendimentos de grande porte que possuem a capacidade de atrair ou produzir uma grande quantidade de viagens. Nesta categoria estão inseridos os seguintes estabelecimentos: centros de emprego, centros comerciais, universidades, atrações turísticas, shopping centers, supermercados, portos, aeroportos, estações de transporte público de massa, praças, parques de lazer, centros de convenções e hotéis.

\subsection{Etapa 2: Identificar os caminhos mínimos entre os pólos geradores de viagens}

Ao definir os caminhos mínimos entre os pólos geradores de viagens, tem-se as seguintes opções:

a) Considerar todos os caminhos mínimos (maior rede cicloviária disponibilizada ao ciclista) para composição do sistema; ou

b) Fazer a interligação entre os pólos geradores de viagens através de um itinerário único interligando todos os pontos (rede simplificada), como um projeto inicial.

A segunda possibilidade apresenta uma alternativa de menor custo para o município, pois compreende uma interligação entre os pólos geradores de viagens através de um caminho único interligando todos os pólos, um circuito, ou seja, uma única rota que ofereça ao usuário ciclista a possibilidade de se deslocar entre os polos.

\subsection{Etapa 3: Qualificação dos segmentos de caminhos mínimos}

Nesta etapa, calcula-se o índice de adequação de cada segmento de via (IAS) que compõe os caminhos mínimos, que compreende:

- Medição e quantificação dos indicadores;

- Cálculo do índice de adequação (IAS);

Conforme já mencionado neste trabalho, alguns indicadores foram escolhidos para compor o IAS dos segmentos. A seguir, apresenta-se a forma de quantificação destes indicadores para cálculo do IAS.

\subsubsection{Quantificação dos indicadores}

Os indicadores propostos foram: largura efetiva da via, estacionamento na via, volume médio de tráfego, velocidade máxima na via e aclive. Visando obter um índice de qualificação numa escala de 0 a 3, já utilizado por Monteiro (2011), propõe-se aplicar um processo de normalização análogo ao proposto por Eastman \& Jiang (1996), em que o valor resultante do indicador esteja entre 0 e 3 . Nesta escala, se o valor apurado para o segmento estiver entre 0 e 1 , quanto ao indicador ou índice, é ruim. Acima de 1 até 2, o segmento apresenta uma situação boa. Quando o resultado apresentar um valor superior a 2, tem-se uma situação muito boa.
Para a quantificação dos segmentos, com base no processo acima, foram definidos alguns valores e formulações para cada um dos indicadores:

- Largura Efetiva da via: a largura é importante para a identificação de qual estrutura pode ser implantada na via (via compartilhada, ciclofaixa ou ciclovia). Os estudos revistos neste trabalho indicam que a largura mínima efetiva deve ser de no mínimo 4,27 m na faixa junto ao meio-fio para uma via compartilhada. As vias urbanas, de acordo com o HCM (TRB, 2010) têm largura aceitável de 3,00 m. Assim sendo, na via compartilhada, o espaço útil para o ciclista é de $1,27 \mathrm{~m}$. Caso a largura total da via apresente valores superiores a 4,27 m, pode-se implantar outro tipo de infraestrutura (ciclofaixa ou ciclovia). A medida mínima para ciclofaixas é de $1,80 \mathrm{~m}$ e para ciclovias é de 2,50 m (Caderno de Referência para elaboração de Plano de Mobilidade por Bicicletas nas Cidades, 2007). Diante disto, pode-se estabelecer as larguras mínimas efetivas para cada tipo de infraestrutura: Via Compartilhada (4,27 m), Ciclofaixa (4,80 m) e Ciclovia $(5,50 \mathrm{~m})$. Com as respectivas adaptações quanto ao número de faixas na via (redução do número de faixas no mesmo sentido ou mudança para sentido único na via), o indicador de largura efetiva $\left(l_{\text {lef }}\right)$ irá variar conforme o tipo de infraestrutura que poderá ser implantada, atendendo ao intervalo de 0 a 3 de acordo com a Tabela 3.

- Estacionamento na via: analisa-se a presença ou permissão de estacionamento de veículos automotores na via. Quanto maior a extensão deste estacionamento, mais insegura é a via para quem usa bicicleta, devido à movimentação de acesso e saída de veículos. Assim, a medida é definida como: a extensão da via sem estacionamento dividida pela extensão total do segmento analisado, conforme a Equação 2.

$$
I_{e s t}=\frac{1-v_{r}}{1-0} \times 3.0 \longrightarrow I_{e s t}=\left(1-v_{r}\right) \times 3.0
$$

Onde:

Iest $=$ Indicador normalizado de estacionamento na via em paralelo

$\mathrm{Vr}=$ Extensão do segmento de via com estacionamento permitido dividido pela extensão total do segmento

- Limite de velocidade na via para veículos automotores: a velocidade máxima que deve ser permitida para veículos automotores em via compartilhadas com bicicletas é de $70 \mathrm{~km} / \mathrm{h}$. assim, considerou-se um valor máximo para velocidade de $70 \mathrm{~km} / \mathrm{h}$ (ver Tabela 4) e um valor mínimo de $20 \mathrm{~km} / \mathrm{h}$ (valor mínimo referencial indicado no código brasileiro de trânsito em função da média das velocidades permitidas de 40 $\mathrm{km} / \mathrm{h}$, representando $50 \%$ deste valor, conforme Equação 3:

$$
I_{v e l}=\frac{v_{\max }-v_{\text {seg }}}{v_{\max }-20} \times 3,0
$$


CARDOSO, P. B.; CAMPOS, V. B. G.

Tabela 3. Valor do indicador $L_{e f}$ de acordo largura efetiva da via

\begin{tabular}{ccccc}
\hline $\begin{array}{c}\text { Largura efetiva da } \\
\text { via (1 faixa) }\end{array}$ & $\begin{array}{c}\text { Largura efetiva da } \\
\text { via (1 faixa) }\end{array}$ & $\begin{array}{c}\text { Largura efetiva da } \\
\text { via (1 faixa) }\end{array}$ & Tipo de Infraestrutura & Lef \\
\hline Até $4,26 \mathrm{~m}$ & Até $7,26 \mathrm{~m}$ & Até $10,26 \mathrm{~m}$ & Nenhuma & 0 \\
$\geq 4,27$ a $4,79 \mathrm{~m}$ & $\geq 7,27$ a $7,79 \mathrm{~m}$ & $\geq 10,27$ a $10,79 \mathrm{~m}$ & Via Compartilhada & 1 \\
$\geq 4,80$ a $5,49 \mathrm{~m}$ & $\geq 7,80$ a $8,49 \mathrm{~m}$ & $\geq 10,80$ a $11,49 \mathrm{~m}$ & Via Compartilhada & 2 \\
$\geq 5,50 \mathrm{~m}$ & $\geq 8,50 \mathrm{~m}$ & $\geq 11,50 \mathrm{~m}$ & Ciclovia & 3 \\
\hline
\end{tabular}

Onde:

Ivel $=$ Indicador de velocidade do segmento

Vmax = Velocidade máxima permitida em vias, conforme tabela 6 .

Vseg $=$ Velocidade máxima no segmento medido

Tabela 4. Relação Fluxo de Veículo e Velocidade Máxima Fonte: Adaptado de CROW, 2011

\begin{tabular}{|c|c|c|}
\hline Estrutura da via & $\begin{array}{l}\text { Fluxo de Veículo } \\
\text { (veículos/hora/faixa) }\end{array}$ & $\begin{array}{l}\text { Velocidade } \\
\text { Máxima } \\
\text { (km/h) }\end{array}$ \\
\hline Via Compartilhada & 0 a 100 & $\leq 70$ \\
\hline Via Compartilhada & 101 a 200 & $\leq 50$ \\
\hline Via Compartilhada & 201 a 300 & $\leq 40$ \\
\hline Via Compartilhada & 301 a 400 & $\leq 35$ \\
\hline Via Compartilhada & 401 a 500 & $\leq 32$ \\
\hline Via Compartilhada & 501 a 780 & $\leq 30$ \\
\hline Via Compartilhada & $\geq 780$ & $\begin{array}{l}\text { Congestiona- } \\
\text { mento causa } \\
\text { desconforto ao } \\
\text { ciclista }\end{array}$ \\
\hline Ciclofaixa & 0 a 100 & $\leq 70$ \\
\hline Ciclofaixa & 101 a 200 & De 45 a 70 \\
\hline Ciclofaixa & 201 a 300 & De 40 a 60 \\
\hline Ciclofaixa & 301 a 400 & De 35 a 56 \\
\hline \multirow[t]{2}{*}{ Ciclofaixa } & 401 a 500 & De 30 a 56 \\
\hline & $\geq 501$ & $30 \mathrm{~km}$ \\
\hline Ciclovia & 0 a 100 & De 70 a 90 \\
\hline Ciclovia & 101 a 200 & De 65 a 69 \\
\hline Ciclovia & 201 a 300 & De 60 a 64 \\
\hline Ciclovia & 301 a 400 & De 56 a 59 \\
\hline Ciclovia & 401 a 600 & De 50 a 55 \\
\hline Ciclovia & $\geq 601$ & De 35 a 49 \\
\hline
\end{tabular}

- Volume médio de tráfego de veículos automotores: quanto maior o volume médio de tráfego, maiores os riscos para os ciclistas. As vias que apresentam volumes superiores a 780 veículos por hora são consideradas inadequadas para o tráfego de bicicletas (CROW, 2011).

Para medida do indicador propõe-se a Equação 4, em que se considera como a melhor situação o volume igual a zero de veículos automotores e a pior situação o volume superior a 780 veículos por hora.

$$
I_{v t}=\frac{780-v t_{\text {seg }}}{780-0} \times 3,0 \longrightarrow I_{v t}=\left(\frac{780-v t_{\text {seg }}}{780}\right) \times 3,0
$$

Onde:

Ivt = Indicador normalizado de volume médio de tráfego do segmento

$\mathrm{Vr}=$ Volume de tráfego automotivo do segmento medido por hora

Caso o valor resultante de Ivt seja negativo assumese o valor 0 (zero) como índice para este parâmetro.

- Aclive: de acordo com AASHTO (1999), a inclinação máxima confortável para o ciclista varia conforme a
Tabela 5, pois depende também da extensão do trecho em aclive. Os aclives devem ser mantidos o mais baixo possível (o ideal é ausência de aclive). Aclives superiores a $5 \%$ devem ser evitados em extensões iguais ou superiores a $240 \mathrm{~m}$. Caso a angulação seja superior a $5 \%$, o trecho a ser percorrido deve ser inferior, conforme a Tabela 5 .

As unidades de medida deste indicador são o greide e extensão deste na via. Considera-se a ausência de aclive a melhor situação e o aclive máximo conforme a Tabela 5 como a pior situação, assim, o valor do indicador normalizado é definido como:

$$
I_{a c}=\frac{C_{a c}-C g_{s e g}}{C_{a c}-0} \times 3,0 \longrightarrow I_{a c}=\left(\frac{C_{a c}-C g_{s e g}}{C_{a c}}\right) \times 3,0
$$

Onde:

Iac $=$ Indicador de aclive do segmento

$\mathrm{Cac}=$ Comprimento máximo do segmento para o valor do greide (Tabela 5)

$\mathrm{Cg}_{\text {seg }}=$ Comprimento do trecho em aclive no segmento medido

Tabela 5. Comprimentos e angulação dos aclives Fonte: Adaptado de AASHTO, 1999

\begin{tabular}{cc}
\hline Aclive & Comprimentos (m) \\
\hline $5 \%$ & $<240$ \\
$6 \%$ & $<180$ \\
$7 \%$ & $<120$ \\
$8 \%$ & $<90$ \\
$9 \%$ & $<60$ \\
$10 \%$ & $<30$ \\
$>11 \%$ & $<15$ \\
\hline
\end{tabular}

Aclive inferior a 5\% considera-se aceitável para qualquer extensão. Sendo assim, conforme a Equação 5 o índice do indicador para neste caso seria 3,0 (três).

\subsection{2. Índice geral de adequação do segmento}

Após a quantificação de cada indicador por segmento deve-se calcular o valor do índice geral de adequação. Este índice é composto pela média aritmética entre todos os indicadores normalizados, conforme mostrado na Equação (6):

$$
I A S=\frac{I_{l e f}+I_{e s t}+I_{v e l}+I_{v t}+I_{a c}}{5}
$$

Onde:

IAS - Índice de adequação do segmento

Ilef - Índice de largura efetiva do segmento

Iest - Índice de estacionamento na via em paralelo

Ivel - Índice do limite de velocidade na via para veículos automotores

Ivt - Índice do volume médio de tráfego de veículos automotores

Iac - Índice do aclive do segmento de via. 
Tabela 6. Classificação dos trechos analisados

\begin{tabular}{c|c}
\hline Índice de Adequação do Trecho & Descrição da classificação do trecho analisado \\
\hline 0,00 a 1,00 & $\begin{array}{c}\text { Segmento ruim cuja utilização dentro do sistema cicloviário não é aconselhada. Trecho } \\
\text { necessita de grandes intervenções e modificações. }\end{array}$ \\
\hline 1,01 a 2,00 & $\begin{array}{c}\text { Segmento bom cujo uso dentro do sistema cicloviário é aconselhado, podendo ser realiza- } \\
\text { das intervenções nos indicadores que tiveram uma avaliação baixa. }\end{array}$ \\
\hline 2,01 a 3,00 & $\begin{array}{c}\text { Segmento ótimo cuja utilização dentro do sistema cicloviário é plenamente aconselhada. } \\
\text { Precisa de pequeníssimas ou nenhuma intervenção nos indicadores que tiveram um menor } \\
\text { resultado }\end{array}$ \\
\hline
\end{tabular}

\subsubsection{Classificação dos segmentos analisados}

Após o cálculo do índice geral de adequação do segmento, a via deverá ser classificada conforme Tabela 6 , que especifica o nível de adequação do segmento da via.

\subsection{Etapa 4 - Avaliação das rotas do sistema cicloviário a ser implantado}

Nesta etapa deve-se identificar os segmentos que obtiveram a classificação "ruim", verificando-se a substituição dos mesmos por segmento ou segmentos próximos. Para isto, calcula-se o caminho mínimo entre os pontos de origem e destino do segmento inadequado (IAS < 1,0); identificando as vias que substituirão os trechos descartados analisando-as com o mesmo índice indicado na Equação 6 e classificando conforme a tabela 6. Caso o (s) segmento (s) substituto (s) seja (m) classificado (s) como "bom (ns)" ou "ótimo(s)", deve-se incluí-lo (s) na rota. Conforme identificado na pesquisa realizada neste estudo, o novo caminho mínimo calculado não deve exceder o percurso original em $30 \%$ na distância total ou em $35 \%$ no tempo de viagem. Caso esta condição não seja atendida, deve-se retornar a

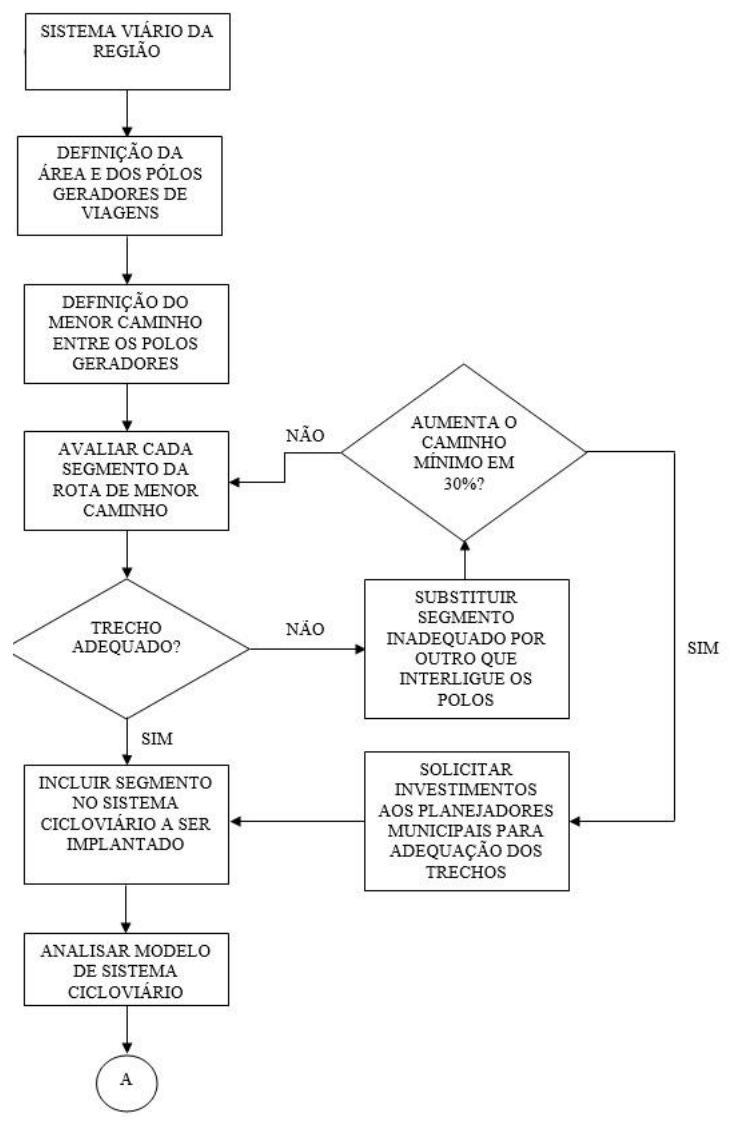

rota original e solicitar investimentos para adequação da via, visando atingir um índice adequado para o segmento.

\subsection{Etapa 5 - Analisar e sugerir melhorias nos segmentos que comporão o sistema cicloviário}

Esta etapa compreende uma análise dos indicadores por segmento visando a implementação de ações que aumentem o índice de adequação do mesmo, permitindo o aumento da segurança e do conforto para os usuários ciclistas. Estas ações devem ser avaliadas pelos planejadores municipais, avaliando os impactos que tais alterações causarão no trânsito local.

Algumas ações simples, podem aumentar o índice de adequação do trecho, como por exemplo:

- Estacionamento na Via: redução ou eliminação do estacionamento na via, aumentando a área para circulação do ciclista.

- Velocidade Máxima da Via: redução do limite de velocidade na via (até o mínimo previsto no Código Brasileiro de Trânsito), ou seja: vias de trânsito rápido $(80 \mathrm{~km} / \mathrm{h})$; vias arteriais $(60 \mathrm{~km} / \mathrm{h}) \mathrm{e}$; vias locais $(40 \mathrm{~km} / \mathrm{h})$.

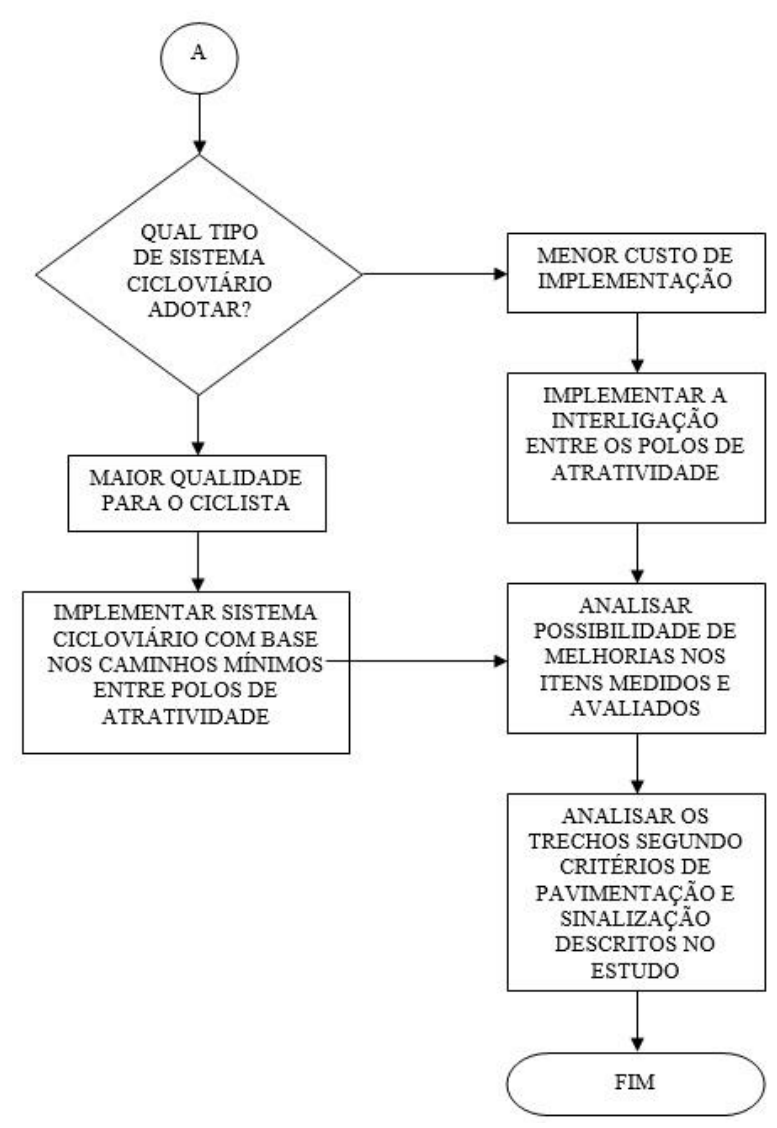

Figura 1. Fluxograma da metodologia 
- Volume Médio de Tráfego por faixa: alterações no sentido do fluxo das vias.

Além disso, quanto aos parâmetros de pavimentação e sinalização (indicados na revisão bibliográfica) considerou-se que são melhorias que no primeiro momento, não devem influenciar diretamente a seleção das rotas, mas sim, na melhoria do sistema cicloviário que está sendo planejado. Assim, nos aspectos relacionados à pavimentação, sugere-se que sejam adotados os critérios descritos nos estudos descritos pelo BSIR (Bycicle Safety Index Rating), desenvolvido por Davis (1987). Nos aspectos relativos à sinalização, devem ser observados de acordo com a legislação de sinalização no Brasil.

\subsection{Fluxograma do Procedimento}

Para melhor entendimento do procedimento proposto apresenta-se na Figura 1 o fluxograma da metodologia para definição das vias que irão compor o sistema cicloviário a ser implantado.

\section{EXEMPLO DE APLICAÇÃO}

O centro da cidade de Nova Iguaçu, localizada no Estado do Rio de Janeiro, foi a área escolhida para aplicação da metodologia. Neste centro foram identificados quatro pólos geradores de viagens: Universidade de Nova Iguaçu (universidade) - Ponto A, Universidade do Grande Rio / Instituto Iguaçuano (universidade e escola) - Ponto B, Centro Comercial Vianense (área comercial) - Ponto C e Estação Ferroviária de Nova Iguaçu (Integração com o Transporte Público) - Ponto D.

Como uma primeira opção, definida na Etapa 2, foram incialmente identificadas as rotas de caminho mínimo entre cada polo, formando uma rede de interligação entre todos os polos. Esta opção (rede de caminhos mínimos) apresentou um sistema cicloviário com um total de 3735 metros. Também foi considerada a segunda opção, um circuito de menor distância formado pela interligação dos polos geradores de viagens, conforme apresentado na figura 2. Esta segunda opção o sistema resultou num total 3415 metros.

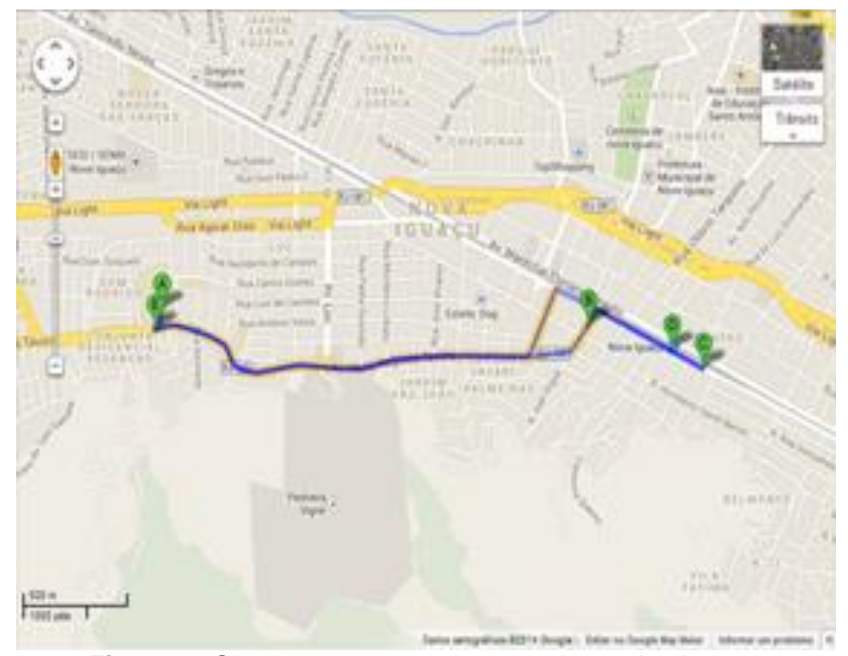

Figura 2. Circuito entre os polos geradores de viagens
Como exemplo de quantificação e medição dos indicadores, apresenta-se na tabela 7 , os valores de cada segmento que forma o caminho mínimo entre os pólos A e B.

Tabela 7. Índice de Adequação dos Segmentos na rede em Nova Iguaçu

Fonte: Cardoso, 2014

\begin{tabular}{|c|c|c|}
\hline Segmento Avaliado & $\begin{array}{c}\text { Índice } \\
\text { Adequação do } \\
\text { Segmento (IAS) }\end{array}$ & $\begin{array}{l}\text { Classificação } \\
\text { do Segmento }\end{array}$ \\
\hline $\begin{array}{l}\text { Av. Abílio Augusto } \\
\text { Távora - Parte A }\end{array}$ & 1,95 & Bom \\
\hline $\begin{array}{l}\text { Av. Abílio Augusto } \\
\text { Távora - Parte B }\end{array}$ & 2,04 & Muito Bom \\
\hline $\begin{array}{c}\text { Rua Dr. Tibau - } \\
\text { Parte A }\end{array}$ & 1,88 & Bom \\
\hline $\begin{array}{c}\text { Rua Bernardino de } \\
\text { Mello - Parte A }\end{array}$ & 1,24 & Bom \\
\hline $\begin{array}{c}\text { Rua Bernardino de } \\
\text { Mello - Parte B }\end{array}$ & 1,31 & Bom \\
\hline $\begin{array}{c}\text { Rua Dr. Tibau - } \\
\text { Parte B }\end{array}$ & 1,64 & Bom \\
\hline $\begin{array}{c}\text { Rua Bernardino de } \\
\text { Mello - Parte C }\end{array}$ & 1,36 & Bom \\
\hline $\begin{array}{l}\text { Rua Bernardino de } \\
\text { Mello - Parte D }\end{array}$ & 1,38 & Bom \\
\hline $\begin{array}{c}\text { Rua Comendador } \\
\text { Soares }\end{array}$ & 1,53 & Bom \\
\hline $\begin{array}{c}\text { Rua Bernardino de } \\
\text { Mello - Parte E }\end{array}$ & 1,06 & Bom \\
\hline $\begin{array}{l}\text { Rua Bernardino de } \\
\text { Mello - Parte FF }\end{array}$ & 1,30 & Bom \\
\hline $\begin{array}{c}\text { Rua Sebastião } \\
\text { Herculano de Matos }\end{array}$ & 1,16 & Bom \\
\hline $\begin{array}{c}\text { Rua Dr. Mário } \\
\text { Guimarães }\end{array}$ & 1,74 & Bom \\
\hline $\begin{array}{c}\text { Rua Dr. Tibau } \\
\text { - Parte B }\end{array}$ & 2,07 & Muito Bom \\
\hline $\begin{array}{c}\text { Rua Bernardino de } \\
\text { Mello - Parte G }\end{array}$ & 1,18 & Bom \\
\hline $\begin{array}{c}\text { Rua Bernardino de } \\
\text { Mello - Parte H }\end{array}$ & 1,18 & Bom \\
\hline $\begin{array}{c}\text { Rua Bernardino de } \\
\text { Mello - Parte I }\end{array}$ & 1,30 & Bom \\
\hline $\begin{array}{c}\text { Rua Dr. Tibau - } \\
\text { Parte C }\end{array}$ & 2,13 & Muito Bom \\
\hline
\end{tabular}

A Tabela 8 apresenta, como exemplo, a avaliação do segmento referente a Avenida Abílio Augusto Távora Parte A, da rota do pólo gerador de viagem A (Universidade Iguaçu) para o pólo gerador de viagem B (Universidade do Grande Rio - Instituto Iguaçuano), que tem uma extensão de $1910 \mathrm{~m}$, sendo uma via de mão dupla sem divisão central.

Tabela 8. Cálculo do índice relativo a Avenida Abílio Augusto Távora - Parte A

\begin{tabular}{c|c|c|c|c}
\hline Índice & $\begin{array}{c}\text { Pior } \\
\text { Valor }\end{array}$ & $\begin{array}{c}\text { Melhor } \\
\text { Valor }\end{array}$ & $\begin{array}{c}\text { Valor } \\
\text { Real }\end{array}$ & $\begin{array}{c}\text { Valor } \\
\text { Normalizado }\end{array}$ \\
\hline ILEV & & & 8,75 & 3,00 \\
\hline IEST & 0 & 1 & 1 & 3,00 \\
\hline IVM & 70 & 20 & 50 & 1,20 \\
\hline IVD & 780 & 0 & 584 & 0,75 \\
\hline IAC & 5 & 0 & 2 & 1,80 \\
\hline \multicolumn{6}{c|}{$\begin{array}{c}\text { Índice Adequação do } \\
\text { Segmento (IAS) }\end{array}$} & 1,95 & BOM \\
\hline
\end{tabular}




\section{CONSIDERAÇÕES FINAIS}

Considera-se que a metodologia colabora para o planejamento adequado de um sistema cicloviário visando ações efetivas de fomento ao uso da bicicleta, sem que estas ações sejam onerosas para o poder público.

Assim, pela simplicidade de aplicação e por englobar indicadores que auxiliam no processo de decisão, além do índice que facilita a identificação de uma rota adequada, a metodologia poderá facilitar a implementação de sistemas cicloviários em médias e grandes cidades.

As etapas propostas na metodologia podem reduzir os erros na escolha das vias que irão compor o sistema cicloviário, pois, a definição dos segmentos viários considera o que foi observado na pesquisa com usuários, que em geral escolhem a rota de no menor tempo de trajeto e/ou na maior sensação de segurança e conforto para os mesmos.

Ressalta-se que a escolha dos indicadores foi baseada nos parâmetros ou critérios mais mencionados na revisão bibliográfica e no questionário realizado, porém, outros podem vir a serem incluídos, caso se considere importante em outras pesquisas. Além disso, também na definição dos pólos geradores de viagem, pode-se incluir os pontos centrais de zonas residenciais, ou mesmo, pontos importantes destas como praças (pólos referenciais). A aplicação neste trabalho teve como objetivo mostrar como poderia ser utilizada a metodologia.

Como sugestão de aprimoramento da metodologia, indica-se um estudo sobre a definição de pesos para cada um dos indicadores propostos, caracterizando a maior relevância de alguns destes. Desta forma, ao invés de uma média dos valores quantificados por segmentos, ter-se-ia um somatório dos pesos vezes os valores.

\section{REFERÊNCIAS}

Cardoso, P.B. (2014) Metodologia para implntação de sistemas Cicloviários. Dissertação no Programa de Mestrado em Engenharia de Transportes do Instituto Militar de Engenharia. Rio de Janeiro

CROW.(2011) "Manual de Diseño Para El Tráfico de Bicicletas”. Ploeger.J \& Kroeze. P.A. Holanda. Disponível em : http://pt.slideshare.net/ArchVicky/crow-record-27-manual-dediseo-para-el-trfico-de-bicicletas-2011-lr

DENATRAN. (2001) Manual de procedimentos para o tratamento de pólos geradores de tráfego. Brasília: DENATRAN/FGV

FHWA (1998) BCI. The Bicycle Compatibility Index: A Level of Service Concept, Implementation Manual. FHWA-RD-98095, Federal Highway Administration, Washington, DC. Disponível em: safety.fhwa.dot.gov/tools/docs/bci.pdf

FHWA - Federal Highway Administration (1979). A bikeway criteria digest: The ABCD's of bikeways.

GEIPOT (2001). Planejamento Cicloviário: Diagnóstico Nacional. Brasília: Empresa Brasileira de Transportes e Trânsito.

Davis, J. (1987) Bicycle Safety Evaluation. Auburn University, City of Chattanooga, and Chattanooga Hamilton County Regional Planning Commission, Chattanooga, TN.

Dixon, L. B.(1996) Bicycle and Pedestrian Level-of-Service Performance Measures and Standards for Congestion
Management Systems. Transportation Research Record n.1538, DOI: $10.3141 / 1538-01$

Eastman J.R. E Jiang, H. ,(1996) “Fuzzy Measures in Multicriteria Evaluation. In: Proceedings, Second International Symposium on Spatial accuracy Assessments in Natural resources Environmental Studies”,,Fort Collins, Colorado. p.527534.

Eddy, N. (1996) Developing a Level of Service for Bicycle Use. Pro Bike/Pro Walk 96 Resource Book. Proceedings of the Ninth International Conference on Bicycle and Pedestrian Programs Resource Book, Bicycle Federation of America and Pedestrian. Federation of America, pp. 310-314.

Ehgott, M. et al (2012). A bi-objective cyclist route choice model. Transportation Research Part A: Policy and Practice, No. 46 Part A, Transportation Research Board, Washington, DC. DOI: $10.1016 /$ j.tra.2011.11.015

Epperson, B. (1994). Evaluating suitability of roadways for bicycle use: toward a cycling level of service standard. Transportation Research Record 1438, 9-16. http://worldcat.org/isbn/0309055199

Fernández-Heredia, A.; Jara-Díaz, S.; Monzón, S. Understanding and modeling bicycle use: the role of perceptions. Transportation, v. 39, n. 2, p. 409-432, Oct. 2014. DOI: 10.1016/j.tra.2014.02.013

GEIPOT - Empresa Brasileira de Planejamento de Transportes. (2001) Planejamento Cicloviário: Observação Nacional. Brasília. 2001.

Heinen, E. B. van Wee, K. Maat Commuting by bicycle: An overview of literature. Transport Reviews, 30 (2010), pp. 59 pp. DOI: $10.1080 / 01441640903187001$

Kirner, J. \& Sanches, S. P. (2008). Method for Establishing Urban Cycling Routes: An Application in São Carlos, Brazil. In: Transportation Research Board 87th Annual Meeting, Washington D. C., USA. http://pubsindex.trb.org/orderform.html

Landis, B. W.; Vattikuti, V. R.; Brannick, M. T.(1997) Real-time human perceptions: toward a bicycle level of service. Transportation Research Record 1578, 119-126. DOI: $10.3141 / 1578-15$

MINISTÉRIO DAS CIDADES. Programa Brasileiro de Mobilidade por Bicicleta - Bicicleta Brasil. Caderno de Referência para Elaboração de Plano de Mobilidade por Bicicleta nas Cidades. Brasília: Ministério das Cidades. 2007b. Disponível em: <www.cidades.gov.br>. Acesso em: 20 nov. 2014.

Monteiro, F.B. (2011)Avaliação de espaços urbanos para pedestres e ciclistas visando a integração com o transporte de massa. Dissertação de Mestrado. Instituto Militar de Engenharia. Rio de Janeiro, Brasil.

Magalhães, J. R. L. \& Palhares, D. A. G. (2013). Utilização do método de preferência declarada para caracterização da demanda pelo transporte cicloviário em Montes Claros/MG. Anais do XXVII Congresso de Ensino e Pesquisa em Transportes, Belém.

Magalhães, J. R. L., Campos, V.B.G., Bandeira, R.A.M. (2015) . Metodologia para identificação de redes de rotas cicláveis em áreas urbanas. Journal of Transport Literature, Vol.9 no3. DOI: 10.1590/2238-1031.jtl.v9n3a7

Richardson, R. J. ( 1999), Pesquisa Social - Métodos e Técnicas. 3a ed. São Paulo: Atlas. 
Segadilha, A.B.P., Sanches, S.P. (2014) Análise de Rotas de Viagem utilizando GPS e SIG. Anais do XXVIII ANPET, Curitiba, Paraná.

Sorton, Alex; Walsh, Thomas (1994). Bicycle Stress Level as a Tool to Evaluate Urban and Suburban Bicycle Compatibility.

Transportation Research Record 1438. TRB, National Research Council, Washington, DC, pp. 17-24.

http://worldcat.org/isbn/0309055199

Providelo, J. K. \& Sanches, S. P. (2011). Roadway and traffic characteristics for bicycling. Transportation, 38(5), 765-777. DOI: http:10.1007/s11116-011-9353-x

TRB. Highway Capacity Manual. (2000) Transportation Research Board, National Research Council, Washington, D.C., EUA.

Vandenbulcke, G.; Thomas, I. Geus, De B.; Degraeuwe, B.;

Torfs, R.; Meeusen, R. e Panis, L.I. (2009) Mapping bicycle use and the risk of accidents for commuters who cycle to workin Belgium. Transport Policy, No.16, 77-87, Washington, DC. DOI: 10.1016/j.tranpol.2009.03.004 